\title{
Diabetes Mellitus Type 2 Screening Guidelines
}

\author{
Mohsen Saberi Isfeedvajani ${ }^{*}$ \\ ${ }^{1}$ Medicine, Quran and Hadith Research Center \& Department of Community Medicine, Faculty of Medicine, Baqiyatallah \\ University of Medical Sciences, Tehran, Iran
}

Corresponding Author: Mohsen Saberi Isfeedvajani, MD, Associate Professor of Community Medicine, Medicine, Quran and Hadith Research Center \& Department of Community Medicine, Faculty of Medicine, Baqiyatallah University of Medical Sciences, Tehran, Iran. Tel: +98-81263617, Email: drsaberihaji@gmail.com

Received October 26, 2018; Accepted November 26, 2018; Online Published December 27, 2018

\begin{abstract}
Diabetes mellitus (DM), a non-communicable disease (NCD), is a major public health challenge worldwide. It is expected that the burden of DM will increase because of population growth, aging, and lifestyle behaviors. Thus, screening guidelines should be developed to prevent mortality and adverse consequences of late detection. In this rapid review, the screening guidelines of DM are reviewed and discussed.

Keywords: Diabetes Mellitus, Type 2, Noncommunicable Diseases, Diagnosis

Citation: Saberi Isfeedvajani M. Diabetes mellitus type 2 screening guidelines. Int J Med Rev. 2018;5(4):137-139. doi:10.29252/IJMR-050401.
\end{abstract}

\section{Introduction}

Diabetes mellitus (DM) is a major public health challenge worldwide. The prevalence of DM has more than doubled globally, ${ }^{1,2}$ and diabetes mortality has also doubled according to global burden of disease (GBD) studies. ${ }^{3,4}$ According to the National Diabetes Statistics Report, 30.3 million people have diabetes (9.4\% of the US population), and 7.2 million people (23.8\%) are undiagnosed. Diabetes was the seventh leading cause of death in the United States in 2015. Unfortunately, 84.1 million adults aged 18 years or older have pre-diabetes (33.9\% of the adult US population). ${ }^{5}$

To prevent the mortality and burden of DM, governmental and scientific associations try to develop and update diabetes guidelines worldwide. In this paper, the guidelines regarding DM are briefly reviewed.

\section{United Stated Preventive Service Task Force}

The United Stated Preventive Service Task Force (USPSTF) has recommended that adults aged 40 to 70 years who are overweight or obese and do not have obvious symptoms of diabetes be screened for abnormal blood glucose levels as part of a cardiovascular risk assessment. People who have a family history of diabetes, a history of gestational DM (GDM) or polycystic ovarian syndrome, or are members of certain racial/ethnic groups (i.e., African Americans, American Indians or Alaskan Natives, Asian Americans, Hispanics or Latinos, or Native Hawaiians or Pacific Islanders) may be at increased risk for diabetes at a younger age or at a lower body mass index. Thus, earlier screening in persons with one or more of these characteristics should be considered by primary healthcare providers or clinicians. ${ }^{6}$

The recommended screening tests are the HbAlc or fasting plasma glucose test or an oral glucose tolerance test (OGTT). Results such as HbAlc $<5.7$, fasting plasma glucose $<100 \mathrm{mg} /$ $\mathrm{dL}$ or $<5.6 \mathrm{mmol} / \mathrm{L}$, and OGTT result after 2 hours $<140 \mathrm{mg} /$ $\mathrm{dL}$ or $7.8 \mathrm{mmol} / \mathrm{L}$ are considered to be normal. An HbAlc $\geq 6.5$, fasting plasma glucose $\geq 126 \mathrm{mg} / \mathrm{dL}$ or $\geq 7.0 \mathrm{mmol} / \mathrm{L}$, and OGTT result after 2 hours $\geq 200 \mathrm{mg} / \mathrm{dL}$ or $\geq 11.1 \mathrm{mmol} / \mathrm{L}$ are considered as type 2 diabetes. Values higher than normal range and lower than diabetes range are considered to indicate impaired fasting glucose (IFG or IGT). It is suggested that adults with normal blood glucose levels be rescreened every 3 years; however, evidence on the optimal rescreening interval for adults with an initial normal glucose test result is limited. The American Association of Family Physicians (AAFP) agrees with the USPSTF's rationale regarding screening for abnormal glucose in overweight or obese adults. ${ }^{6}$

\section{American Diabetes Association}

Based on the standards for the medical care of diabetes, the screening tests of HbAlc or fasting plasma glucose or an OGTT are recommended. The values for diagnoses of normal, IFG, or IGT and type 2 diabetes are the same as those of the USPSTF. It is recommended that adults of any age who are overweight or obese (body mass index [BMI] $\geq 25$ $\mathrm{kg} / \mathrm{m}^{2}$ or $\geq 23 \mathrm{~kg} / \mathrm{m}^{2}$ in Asian Americans) and who have one or more additional risk factors for diabetes be screened. Risk factors include physical inactivity; first-degree relative with

Copyright (C) 2018 The Author(s). This is an open-access article distributed under the terms of the Creative Commons Attribution License (http:// creativecommons.org/licenses/by/4.0), which permits unrestricted use, distribution, and reproduction in any medium, provided the original work is properly cited. 
diabetes; high-risk race/ethnicity (e.g., African American, Latino, Native American, Asian American, Pacific Islander); women who have delivered a baby weighing $>9 \mathrm{lb}$ or were diagnosed with GDM; hypertension $(\geq 140 / 90 \mathrm{~mm} \mathrm{Hg}$ or on therapy for hypertension); an HDL cholesterol level $<35$ $\mathrm{mg} / \mathrm{dL}(0.90 \mathrm{mmol} / \mathrm{L})$ and/or a triglyceride level $>250 \mathrm{mg} /$ $\mathrm{dL}(2.82 \mathrm{mmol} / \mathrm{L})$; women with polycystic ovary syndrome (PCOS); HbA1C $\geq 5.7 \%$, IGT, or IFG on previous testing; and other clinical conditions associated with insulin resistance (e.g., severe obesity, acanthosis nigricans). For all patients, particularly those who are overweight or obese, testing should begin at the age of 45 years. It is recommended that tests be repeated at intervals of no more than 3 years if normal results are obtained.?

Asymptomatic children or adolescents should be screened if they are overweight $(\mathrm{BMI}>85$ th percentile for age and sex, weight for height $>85$ th percentile, or weight $>120 \%$ of ideal for height) and have any two risk factors, e.g., family history of type 2 diabetes in first- or second-degree relative; race/ethnicity (Native American, African American, Latino, Asian American, Pacific Islander); signs of insulin resistance or conditions associated with insulin resistance (acanthosis nigricans, hypertension, dyslipidemia, PCOS, or smallfor-gestational-age birth weight); or maternal history of diabetes or GDM during the child's gestation. It is further recommended that screening be initiated at 10 years of age or at onset of puberty, if puberty occurs at a younger age, and that screening be repeated every 3 years. $^{7}$

\section{American Association of Clinical Endocrinologists}

Based on the American Association of Clinical Endocrinologists (AACE) and American College of Endocrinology (ACE) 2015 clinical practice guidelines for developing a DM comprehensive care plan, screening should be considered in the presence of risk factors for DM. ${ }^{8}$ The risk factors are age $\geq 45$ years without other risk factors; cardiovascular diseases or family history of type $2 \mathrm{DM}$; overweight or obese (BMI 25 to $<30 \mathrm{~kg} / \mathrm{m} 2$ or BMI $\geq 30$ ); sedentary lifestyle; member of an at-risk racial or ethnic group: Asian, African American, Hispanic, Native American (Alaska Natives and American Indians), or Pacific Islander; HDL-C $<35 \mathrm{mg} / \mathrm{dL}(0.90 \mathrm{mmol} / \mathrm{L})$ and/or a triglyceride level $>250 \mathrm{mg} / \mathrm{dL}(2.82 \mathrm{mmol} / \mathrm{L})$; IGT, IFG, and/or metabolic syndrome; PCOS, acanthosis nigricans, non-alcoholic fatty liver disease (NAFLD); hypertension (BP >140/90 mm $\mathrm{Hg}$ or on therapy for hypertension); history of gestational diabetes or delivery of a baby weighing more than $4 \mathrm{~kg}(9 \mathrm{lb})$; antipsychotic therapy for schizophrenia and/or severe bipolar disease; chronic glucocorticoid exposure; sleep disorders in the presence of glucose intolerance (HbAlc $>5.7 \%$, IGT, or IFG on previous testing), including obstructive sleep apnea (OSA), chronic sleep deprivation, and night-shift occupation. ${ }^{8}$

The recommended screening tests are the HbAlc or fasting plasma glucose or an OGTT. The values used for diagnoses of normal, IFG or IGT, or type 2 diabetes are the same as those of the USPSTF except for HbAlc; an HbAlc <5.5\% is considered normal. Individuals at risk for DM whose glucose values are in the normal range should be screened every 3 years. Clinicians may consider annual screening for patients with 2 or more risk factors. ${ }^{8}$

\section{Canadian Task Force on Preventive Health Care}

Based on the Canadian Task Force on Preventive Health Care (CTFPHC) guidelines, routine screening is not necessary for adults at low to moderate risk of diabetes. For adults at a high risk for diabetes, screening every $3-5$ years with $\mathrm{HbAlc}$ is recommended. Adults at a very high risk for diabetes should be screened annually with HbAlc. Risk of diabetes is calculated using the FINDRISC (Finnish Diabetes Risk Score) or CANRISK (Canadian Diabetes Risk Assessment Questionnaire). Age, obesity, history of elevated glucose levels, history of hypertension, family history of diabetes, limited activity levels, and diet with limited intake of fruits and vegetables are considered in FINDRISC and CANRISK. Based on the risk calculator, the risk of developing diabetes within 10 years is classified as low risk $=1 / 100-1 / 25(1 \%-4 \%)$; moderate risk $=1 / 6(17 \%)$; high risk $=1 / 3(33 \%)$; very high risk $=1 / 2(50 \%)$. In adults $\geq 18$ years of age, it is recommended to calculate the risk at least every 3-5 years. ${ }^{9}$

Although $\mathrm{HbAlc}$ is recommended as the preferred blood test, fasting glucose and the OGTT are acceptable alternatives. Based on CTFPHC, an HbA1c level of $6.5 \%$ or greater is the acceptable threshold for diagnosing diabetes; however, values less than $6.5 \%$ do not exclude diabetes diagnosed using glucose tests. ${ }^{9}$

\section{National Institute for Health and Care Excellence}

Based on the UK National Screening Committee (UKNSC) guidelines, universal or population-based screening for type 2 diabetes is not recommended, because earlier diagnosis does not lead to improvements in health outcomes. Moreover, current prevention methods (such as encouraging lifestyle change) have limited effects on correcting the problem. Many improvements in the care and treatment of diabetes have been made, and current convenient testing methods are effective., ${ }^{2,10}$

\section{The Royal Australian College of General Practitioners}

Based on the guidelines for preventive activities in general practice published by the Royal Australian College of General Practitioners (RACGP), persons at high risk should be screened for diabetes every three years from the age of 40 years. Albeit, Aboriginal and Torres Strait Islander peoples should have their risk of diabetes assessed every three years from the age of 18 years. It is recommended that the Australian type 2 diabetes risk assessment tool (AUSDRISK) be performed. Based on the AUSDRISK, scores of $\leq 5,6-11$, and $\geq 12$ are considered as low risk, moderate risk, and high risk, respectively. The conditions that put a person in the high risk category are being $\geq 40$ years of age and being overweight or obese; having a first-degree relative with diabetes; being of a high-risk race/ethnicity (Indian subcontinent or Pacific Islanders); having a history of a previous cardiovascular event (e.g., acute myocardial infarction or stroke); being a woman with a history of GDM; being a woman with PCOS; 
consuming antipsychotic drugs; and having an impaired glucose tolerance test or impaired fasting glucose (not limited by age). ${ }^{11}$

The screening tests recommended for adults at high risk are fasting blood glucose or HbAlc. It is recommended that patients with IGT or IFG be screened every 12 months. Fasting blood glucose levels of $<5.5 \mathrm{mmol} / \mathrm{L}, 6.1-6.9 \mathrm{mmol} / \mathrm{L}$, and $\geq 7$ are considered as normal, IFG, and diabetes, respectively. An $\mathrm{HbAlc}$ of $\geq 48 \mathrm{mmol} / \mathrm{mol}$ (6.5\%) is considered as diabetes. Based on OGTT, a two-hour plasma glucose of $\geq 11.1 \mathrm{mmol} / \mathrm{L}$ is considered as diabetes, while a two-hour plasma glucose between 7.8 and $11.0 \mathrm{mmol} / \mathrm{L}$ and a two-hour result of $<7.8$ $\mathrm{mmol} / \mathrm{L}$ are considered IGT and normal, respectively. ${ }^{11}$

\section{Conclusions}

While DM screening guidelines could be important in reducing the diabetes burden of disease, early diagnosis, and better management, it is important to consider their benefits and harms, direct and indirect costs, accessibility, and the acceptability of the physician and the population.

\section{Conflict of Interest Disclosures}

The author declares that he has no conflicts of interest.

\section{References}

1. Chen L, Magliano DJ, Zimmet PZ. The worldwide epidemiology of type 2 diabetes mellitus--present and future perspectives. Nat Rev Endocrinol. 2011;8(4):228-236. doi:10.1038/nrendo.2011.183.

2. Gray LJ, Willis A, Webb D, Davies MJ, Khunti K. Screening for Diabetes and Prediabetes. In: Bonora E, DeFronzo R, eds. Diabetes.
Epidemiology, Genetics, Pathogenesis, Diagnosis, Prevention, and Treatment. Springer; 2018:1-33. doi:10.1007/978-3-319-273174_12-1.

3. Lozano R, Naghavi M, Foreman K, et al. Global and regional mortality from 235 causes of death for 20 age groups in 1990 and 2010: a systematic analysis for the Global Burden of Disease Study 2010. Lancet. 2012;380(9859):2095-2128. doi:10.1016/s01406736(12)61728-0.

4. Bhutani J, Bhutani S. Worldwide burden of diabetes. Indian J Endocrinol Metab. 2014;18(6):868-870. doi:10.4103/22308210.141388 .

5. Centers for Disease Control and Prevention (CDC). National diabetes statistics report, 2017. Atlanta, GA: CDC; 2017.

6. Siu AL. Screening for Abnormal Blood Glucose and Type 2 Diabetes Mellitus: U.S. Preventive Services Task Force Recommendation Statement. Ann Intern Med. 2015;163(11):861-868. doi:10.7326/ m15-2345.

7. American Diabetes Association. Standards of medical care in diabetes-2015 abridged for primary care providers. Clin Diabetes. 2015;33(2):97-111. doi:10.2337/diaclin.33.2.97.

8. Handelsman Y, Bloomgarden ZT, Grunberger G, et al. American association of clinical endocrinologists and american college of endocrinology - clinical practice guidelines for developing a diabetes mellitus comprehensive care plan - 2015. Endocr Pract. 2015;21 Suppl 1:1-87. doi:10.4158/EP15672.GL.

9. Pottie K, Jaramillo A, Lewin G, et al. Recommendations on screening for type 2 diabetes in adults. CMAJ. 2012;184(15):16871696. doi:10.1503/cmaj.120732.

10. National Screening Committee (NSC). UK NSC Type 2 diabetes screening recommendation. UK: NSC; 2014. https:// legacyscreening.phe.org.uk/diabetes. Accessed January 9, 2019.

11. The Royal Australian College of General Practitioners (RACGP). Guidelines for preventive activities in general practice. 9th ed. East Melbourne, Australia: The Royal Australian College of General Practitioners Ltd; 2018. 